\title{
Statistical Technique
}

National Cancer Institute

\section{Source}

National Cancer Institute. Statistical Technique. NCI Thesaurus. Code C19044.

A method of analyzing or representing statistical data; a procedure for calculating a statistic. 